\title{
Retrograde Endoscopic Delivery of Botulinum Toxin for Anal Fissures
}

Injection of Botox (Allergan, Irvine, California, USA) into the internal anal sphincter (IAS) has been shown to be successful in the treatment of chronic anal fissures and other spastic anorectal disorders [13]. The current injection technique involves using two or three fingers to separate the anal canal and carefully palpate the IAS to ensure correct placement. This technique can be quite painful in patients with anal fissures, and puts the physician at risk for needle-stick injury. Also, blind injections into the IAS may be inaccurate, with the potential for inadvertent injection into the external sphincter. Because of these problems, we have utilized a technique previously described for injection of rectal varices and made adaptations for the endoscopic injection of Botox into the IAS.

With the endoscopic technique, the patient is prepared for sigmoidoscopy in the standard fashion. Using $2 \%$ lidocaine jelly for lubrication, a standard upper endoscope is passed into the rectum. The scope is retroflexed and the dentate line is visualized. The rectum is washed by flushing $100 \mathrm{ml}$ of $10 \%$ povidone- $1 \%$ iodine solution through the working channel and removing it using suction. With the scope in the retroflexed position, the area of the IAS just proximal to the dentate line is injected in a four-quadrant fashion with 1.00 to $1.25 \mathrm{ml}$ of Botox solution (20 to 25 units per injection for a total of 100 units), using a 4-mm sclerotherapy needle. If a fissure is clearly visualized, two of the injections are placed on either side of the fissure. Injections are administered as deeply as possible with the sclerotherapy needle, to inject into the muscle rather than the subcutaneous tissue.

After we had utilized this technique in 22 consecutive patients, 20 of them (91\%) reported symptomatic improvement after 1-2 treatments, which is similar to reported outcomes from other authors using the standard technique [1-3]. While only two patients in our series had

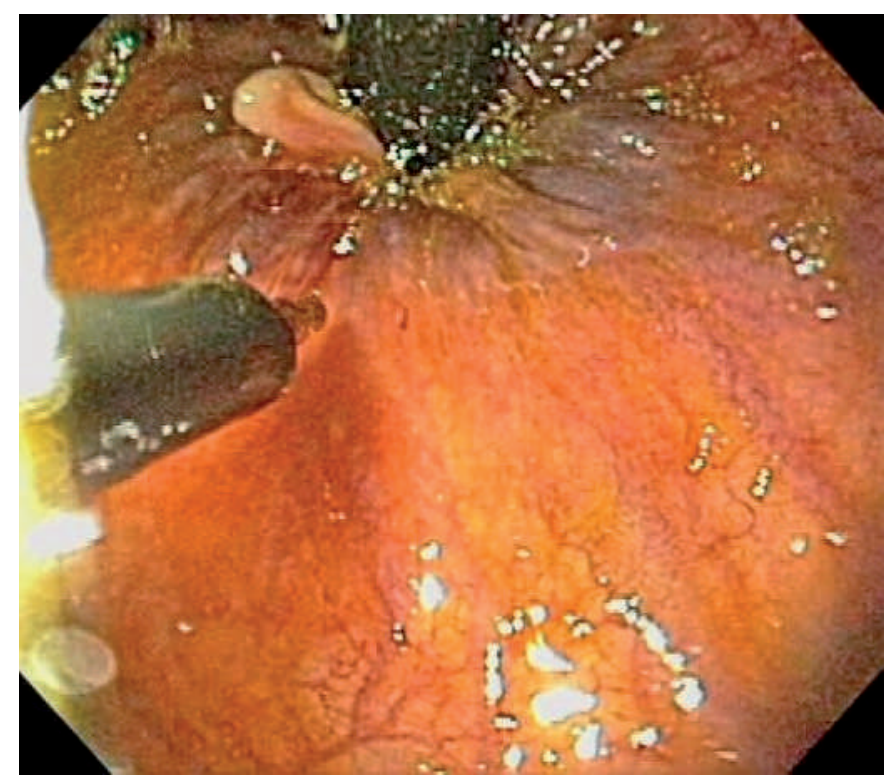

Figure 1 Retrograde endoscopic injection of Botox into the internal anal sphincter, using the dentate line as a guide.

previously received manual Botox injection, both stated a strong preference for the endoscopic technique, and it is our experience that the endoscopic technique is much better tolerated by patients. In summary, we believe endoscopic injection of Botox is more accurate and better tolerated by patients and therefore should supplant the manual technique.

\section{Endoscopy_UCTN_Code_TTT_1AQ_2AI}

\section{T. P. Kinney, A. G. Shah, B. H. G. Rogers,}

\section{E. D. Ehrenpreis}

University of Chicago Medical Center, Chicago, Illinois, USA.

\section{References}

\footnotetext{
${ }^{1}$ Maria G, Cassetta E, Gui D et al. A comparison of botulinum toxin and saline for the treatment of chronic anal fissure. N Engl J Med 1998; 338: 217-220

2 Maria G, Brisinda G, Bentivoglio AR et al. Botulinum toxin in the treatment of outlet obstruction constipation caused by puborectalis syndrome. Dis Colon Rectum 2000; 43: $376-380$

${ }^{3}$ Joo JS, Agachan F, Wolff B et al. Initial North American experience with botulinum toxin type A for treatment of anismus. Dis Colon Rectum 1996; 39: 1107-1111
}

\section{Corresponding Author}

\section{T. P. Kinney, M.D.}

University of Chicago Medical Center 5841 S. Maryland Ave., MC 4076

Chicago, IL 60637

USA

Fax: $\quad+1-773-702-2182$

E-mail: tkinney@medicine.bsd. uchicago.edu 